PRÁTICAS EDUCATIVAS, MEMÓRIAS E ORALIDADES

Rev. Pemo - Revista do PEMO

\title{
Educação feminina no Brasil: o que dizem as pesquisas publicadas no Portal da Capes (2015-2019)
}

\author{
Francinalda Machado Stascxak \\ Universidade Estadual do Ceará, Fortaleza, CE, Brasil \\ Maria Julieta Fai Serpa e Salesii \\ Universidade Estadual do Ceará, Fortaleza, CE, Brasil
}

\begin{abstract}
Resumo
O objetivo deste estudo foi construir um inventário das produções científicas publicadas no Portal de Periódicos CAPES/MEC, referente à educação feminina no Brasil, no recorte temporal de 2015 a 2019. O itinerário metodológico respaldou-se na pesquisa denominada Estado da Arte (FERREIRA, 2002; ROMANOWSKI; ENS, 2006), amparado na Análise de conteúdo (BARDIN, 2011). Desse percurso, resultaram vinte artigos que propiciaram a elaboração de três categorias: "História da Educação", "Publicações" e "Práticas docentes". As pesquisas inventariadas aqui neste estudo tecem reflexões pertinentes à formação e ao trabalho docente de mulheres, invisibilizadas por longo período na historiografia. Ainda que o quantitativo de trabalhos aqui mapeados seja reduzido, é possível concluir que as histórias de educadoras perfazem a História da Educação no Brasil, mas ainda carecem ser descortinadas, haja vista a amplitude de possibilidades que o contexto oferece.
\end{abstract}

Palavras-chave: Educação feminina. Estado da Arte. Produção do conhecimento.

\section{Women's education in Brazil: what the research published on the Capes Portal says (2015-2019)}

\begin{abstract}
The aim of this study was to build an inventory of scientific productions published in the CAPES/MEC Journal Portal, referring to women's education in Brazil, in the time frame from 2015 to 2019. The methodological itinerary was based on the research called State of the Art (FERREIRA, 2002; ROMANOWSKI; ENS, 2006), supported in Content Analysis (BARDIN, 2011). From this path, twenty articles resulted that provided the elaboration of three categories: "History of Education", "Publications" and "Teaching Practices". The researches inventoried here in this study weave reflections pertinent to the training and teaching work of women, invisible for a long period in historiography. Although the number of works mapped here is reduced, it is possible to conclude that the stories of educators make up the History of Education in Brazil, but they still need to be unveiled, given the breadth of possibilities that the context offers.
\end{abstract}

Keywords: Women's education. State of the Art. Knowledge production.

\section{Introdução}

Rev. Pemo, Fortaleza, v. 2, n. 2, p. 1-15, 2020

DOI: https://doi.org/10.47149/pemo.v2i2.3598

https://revistas.uece.br/index.php/revpemo

ISSN: 2675-519X

(c) (i) Esta obra está licenciada com uma Licença Creative Commons

Atribuição 4.0 Internacional. 
Rev. Pemo - Revista do PEMO

\begin{abstract}
A história das mulheres mudou. Em seus objetos, em seus pontos de vista. Partiu de uma história do corpo e dos papéis desempenhados na vida privada para chegar a uma história das mulheres no espaço público da cidade, do trabalho, da política, da guerra, da criação. Partiu de uma história das mulheres vítimas para chegar a uma história das mulheres ativas, nas múltiplas interações que provocam a mudança. Partiu de uma história das mulheres para tornar-se mais especificamente uma história de gênero, que insiste nas relações entre os sexos e integra a masculinidade. Alargou suas perspectivas espaciais, religiosas, culturais.
\end{abstract}

(Perrot, 2019, p. 15-16)

A epígrafe acima, extraída da obra Minha história das mulheres, de Michelle Perrot, introduz a dimensão do universo feminino, deixado à margem da historiografia. Não se trata, portanto, de enfatizar o papel de vítima pelas circunstâncias de outrora, mas de colocar a magnitude da mulher em perspectiva, fazendo emergir, assim, uma seara de múltiplas possibilidades de estudo, atribuindo protagonismo aos percursos das mulheres no campo educacional. Um olhar imprescindível para a compreensão dos limites e possibilidades de atuação feminina no mundo permeado de tensões e contradições, resgatando o ímpeto que impulsiona mudanças, conclamando novos olhares para o tema no sentido de inquietar-se, mobilizando uma reflexão crítica (RIOS, 2010).

As instituições escolares guardam em suas histórias, a impressões sociais de seu tempo e das interações ali impressas (BEGO, 2016). Os modelos escolares existentes até meados do século $X X$ traziam diferenciações no currículo que se pautavam pelo gênero dos estudantes. Nessa linha, abrangia leitura e escrita para ambos os sexos e ensino da matemática mais avançada, restrita para os meninos. Às meninas, eram reservados 0 ensino de matemática elementar e trabalhos manuais, como bordados e costuras (LOPES, 2019). Tornando evidente o caráter dicotômico que o sistema educacional imprimia naquele período.

Essa abordagem diferenciada na educação brasileira, pode-se dizer, que é a ampliação das diferenças entre os sexos, como forma de cristalizar ideias machistas que fortalecem distinções entre os sexos (RIOS, CARDOSO E DIAS, 2018), perpetuando-se a

Rev. Pemo, Fortaleza, v. 2, n. 2, p. 1-15, 2020

DOI: https://doi.org/10.47149/pemo.v2i2.3598

https://revistas.uece.br/index.php/revpemo

ISSN: 2675-519X

(c) (i) Esta obra está licenciada com uma Licença Creative Commons

Atribuição 4.0 Internacional. 
Rev. Pemo - Revista do PEMO

concepção de que homens e mulheres não possuem capacidades mentais equivalentes. Conforme Lima e Santos (2018, p. 153), essas diferenças ressaltam a construção de padronizações "construídas na dimensão coletiva e impostas aos indivíduos", ou seja, limita a autonomia de uns através da supremacia de outros.

Refletindo sobre a questão da educação feminina e de como a mulher faz parte do contexto educacional (SOARES; VIANA, 2016), o escopo deste estudo consistiu em construir um inventário das produções científicas publicadas no Portal de Periódicos CAPES/MEC, referente à educação feminina no Brasil, no recorte temporal de 2015 a 2019, tema articulado aos contextos - histórico, social, político, econômico - certamente imbricados. De caráter bibliográfico, este estudo concretizou-se a partir da metodologia da pesquisa denominada Estado da Arte (FERREIRA, 2002; ROMANOWSKI; ENS, 2006), amparado na Análise de conteúdo (BARDIN, 2011). Para este fim, as buscas realizadas no Portal de Periódicos da CAPES/MEC com os descritores "história da educação" e "mulher" retornaram o quantitativo de 76 artigos publicados em periódicos nos últimos cinco anos. Desse total, somente 20 artigos serão utilizados neste estudo.

Observa-se, por conseguinte, que a parca quantidade de publicações envolvendo a temática da mulher nos seus múltiplos percursos formativos e educativos aponta para a necessidade de mais estudos que tragam em seu bojo discussões que concernem à essencialidade do papel feminino, sobretudo, na educação brasileira.

No que concerne à organização do artigo, o texto foi estruturado em quatro seções, sendo a primeira, a introdução, espaço em que se realiza um breve apanhado da temática e o escopo da pesquisa. A segunda parte, dedicada à metodologia, sistematiza as etapas para obtenção dos dados que viabilizou a construção deste estudo. Na terceira, são apresentados os resultados e a discussão à luz dos pesquisadores, autores dos artigos selecionados. A quarta e última seção traz as considerações finais e as reflexões sobre o que já se produziu acerca dessa temática, bem como aponta lacunas que sugerem novas perspectivas de estudos nesse campo do saber.

\section{Metodologia}




\title{
PRÁTICAS EDUCATIVAS, MEMÓRIAS E ORALIDADES
}

\author{
Rev. Pemo - Revista do PEMO
}

Amparada em uma perspectiva de estudo do campo social, a pesquisa qualitativa dá conta dos aspectos subjetivos que envolvem a produção de novos conhecimentos, bem como fornece novas perspectivas de leitura do mundo e dos sujeitos nele envolvidos (GUEDIN; FRANCO, 2011). A metodologia deste estudo, do tipo Estado da Arte, caracteriza-se como pesquisa bibliográfica, já que se propõe a mapear as produções científicas a partir de outros estudos realizados, registrar lacunas, bem como enfatizar o aporte na área do conhecimento em que se pretende pesquisar (ROMANOWSKI; ENS, 2006). Como bem complementa Ferreira (2002, p. 258), um estudo como o Estado da Arte possibilita "responder que aspectos e dimensões vêm sendo destacados e privilegiados em diferentes épocas e lugares, de que formas e em que condições têm sido produzidas". É um estudo que permite a busca por incoerências, contradições e divergências em que o pesquisador realiza uma análise comparativa de várias posições acerca de um tema com o intuito primeiro de encontrar lacunas nas pesquisas disponíveis.

Como reportado anteriormente, o estudo ora aqui proposto, consistiu no inventário dos artigos científicos publicados em revistas científicas nos últimos cinco anos (20152019) que abordam a formação feminina ao longo da história da educação nos mais variados aspectos que esta temática possa fornecer. Para isso, foi consultada a base de dados do Portal de Periódicos da CAPES/MEC. A análise concentrou-se na quantidade de artigos publicados, nas temáticas, nas abordagens e nas metodologias. Em suma, o percurso metodológico deu-se nas seguintes etapas, a saber:

- Consulta realizada no mês de maio de 2020, no Portal de Periódicos da CAPES/MEC com busca avançada utilizando os descritores "história da educação" e "mulher"; com "qualquer"; "contém"; "and"; data de publicação: "últimos 5 anos"; tipo de material: "artigos"; idioma: "qualquer idioma". O montante de artigos foi de 78 trabalhos. Inicialmente, pensou-se em refinar os resultados incluindo o tópico "Education", porém, retornou apenas 30 artigos, sendo assim, decidiu-se retirar esse refinamento;

- Arquivamento e elaboração de quadro com ênfase nos títulos e nas palavraschave dos artigos resultantes da pesquisa a fim de selecionar os produtos que

Rev. Pemo, Fortaleza, v. 2, n. 2, p. 1-15, 2020

DOI: https://doi.org/10.47149/pemo.v2i2.3598

https://revistas.uece.br/index.php/revpemo

ISSN: 2675-519X

(c) (i) Esta obra está licenciada com uma Licença Creative Commons

Atribuição 4.0 Internacional. 
Rev. Pemo - Revista do PEMO

tivessem alguma abordagem ao tema pretendido. Nessa etapa, resultaram 32 artigos;

- Leitura flutuante dos resumos dos artigos selecionados que resultou em 20 produtos;

- Análise dos dados através da técnica de análise de conteúdo, que culminou com a elaboração de três categorias.

Após as etapas de leitura, classificação e seleção, os 20 trabalhos eleitos para integrar o Estado da Arte estão dispostos no quadro abaixo seguindo as especificações de cada artigo em ordem cronológica, ressaltando o título, a autoria, o nome do periódico e o ano de publicação.

Quadro 1: Artigos encontrados que abordam o tema mulher e educação (2015-2019)

\begin{tabular}{|c|c|c|c|}
\hline TÍTULO & AUTORIA & PERIÓDICO & ANO \\
\hline $\begin{array}{l}\text { Ginástica alemã e ginástica feminina moderna: } \\
\text { práticas destinadas às mulheres }\end{array}$ & $\begin{array}{l}\text { BEGOSSI; } \\
\text { MAZO }\end{array}$ & Cinergis & 2015 \\
\hline $\begin{array}{l}\text { "De volta ao começo": A (re) construção da } \\
\text { trajetória e contribuições da educadora Anália } \\
\text { Franco }\end{array}$ & $\begin{array}{l}\text { SANTANA; } \\
\text { MACIEL; } \\
\text { SOUZA }\end{array}$ & $\begin{array}{l}\text { InterEspaço: Revista } \\
\text { de Geografia e } \\
\text { Interdisciplinaridade }\end{array}$ & 2015 \\
\hline $\begin{array}{l}\text { Fontes para história da alimentação e } \\
\text { patrimônio alimentar: a coluna "Vamos preparar } \\
\text { os quitutes", no Jornal das Moças, nos anos } \\
1950\end{array}$ & PILLA & $\begin{array}{l}\text { Demetra: } \\
\text { alimentação, nutrição } \\
\text { \& saúde }\end{array}$ & 2015 \\
\hline $\begin{array}{l}\text { Os entrecruzamentos das lutas feministas pelo } \\
\text { voto feminino e por educação na década de } \\
1920\end{array}$ & GALVÃO & $\begin{array}{l}\text { Revista Direito \& } \\
\text { Práxis }\end{array}$ & 2015 \\
\hline $\begin{array}{l}\text { Entre arquivos e memórias: o acervo do } \\
\text { Colégio Municipal Pelotense e a inserção de } \\
\text { professoras secundaristas }\end{array}$ & $\begin{array}{c}\text { XAVIER; } \\
\text { WEIDUSCHADT }\end{array}$ & $\begin{array}{l}\text { Resgate: Revista } \\
\text { Interdisciplinar de } \\
\text { Cultura }\end{array}$ & 2016 \\
\hline $\begin{array}{l}\text { Possíveis fontes da estratégia didática de Betti } \\
\text { Katzenstein }\end{array}$ & $\begin{array}{c}\text { BORSATO; } \\
\text { CUNHA }\end{array}$ & História e Cultura & 2016 \\
\hline $\begin{array}{l}\text { Educação e docência feminina no Brasil do } \\
\text { Século XIX: avanços e desafios }\end{array}$ & $\begin{array}{c}\text { GATI; } \\
\text { MONTEIRO }\end{array}$ & $\begin{array}{l}\text { Cadernos de História } \\
\text { da Educação }\end{array}$ & 2016 \\
\hline $\begin{array}{l}\text { Educação, gênero e higienismo nos anúncios } \\
\text { publicitários da Paraíba durante a Primeira } \\
\text { República }\end{array}$ & $\begin{array}{l}\text { VASCONCELOS; } \\
\text { FIALHO; } \\
\text { MACHADO }\end{array}$ & $\begin{array}{l}\text { Cadernos de História } \\
\text { da Educação }\end{array}$ & 2017 \\
\hline $\begin{array}{l}\text { Educação e emancipação feminina em Celina } \\
\text { Padilha, a "educadora transviada" (1927-1930 }\end{array}$ & $\begin{array}{l}\text { DIAS; } \\
\text { JARA }\end{array}$ & $\begin{array}{l}\text { Revista Educação e } \\
\text { Emancipação }\end{array}$ & 2017 \\
\hline $\begin{array}{l}\text { Educação formativa de uma líder política } \\
\text { cearense: Maria Luiza Fontenele (1950-1965) }\end{array}$ & $\begin{array}{l}\text { FIALHO; } \\
\text { FREIRE }\end{array}$ & $\begin{array}{l}\text { Cadernos de História } \\
\text { da Educação }\end{array}$ & 2018 \\
\hline
\end{tabular}

Rev. Pemo, Fortaleza, v. 2, n. 2, p. 1-15, 2020

DOI: https://doi.org/10.47149/pemo.v2i2.3598

https://revistas.uece.br/index.php/revpemo

ISSN: 2675-519X

(c) (i) Esta obra está licenciada com uma Licença Creative Commons

Atribuição 4.0 Internacional. 
PRÁTICAS EDUCATIVAS, MEMÓRIAS E ORALIDADES

Rev. Pemo - Revista do PEMO

\begin{tabular}{|c|c|c|c|}
\hline $\begin{array}{l}\text { Para além das prendas domésticas: a trajetória } \\
\text { da mestra Benedita da trindade no magistério } \\
\text { feminino paulista }\end{array}$ & MUNHOZ & $\begin{array}{l}\text { Revista Brasileira de } \\
\text { História da Educação }\end{array}$ & 2018 \\
\hline $\begin{array}{l}\text { Contornos da educação feminina: a proposta } \\
\text { educativa do educandário Nossa Senhora da } \\
\text { Piedade, } 1925-1930\end{array}$ & $\begin{array}{l}\text { NETO; } \\
\text { HORA }\end{array}$ & Periferia & 2018 \\
\hline $\begin{array}{l}\text { Personagens femininas do livro paradidático } \\
\text { "Tosco": educação sobre gênero e identidade }\end{array}$ & $\begin{array}{l}\text { CUNHA; } \\
\text { SILVA }\end{array}$ & Periferia & 2018 \\
\hline $\begin{array}{l}\text { Educação profissional da mulher e a ascensão } \\
\text { a cargos de liderança }\end{array}$ & RODRIGUES & Revista Labor & 2018 \\
\hline $\begin{array}{l}\text { Memórias de normalistas: inserção profissional } \\
\text { de professoras }\end{array}$ & MELO & $\begin{array}{l}\text { Cadernos de História } \\
\text { da Educação }\end{array}$ & 2019 \\
\hline $\begin{array}{l}\text { As mulheres e a enologia no sul do país: a } \\
\text { história do Colégio de Viticultura e Enologia na } \\
\text { cidade de Bento Gonçalves-RS, Brasil (1959- } \\
\text { 2019) }\end{array}$ & $\begin{array}{l}\text { CAMARGO; } \\
\text { EGGERT }\end{array}$ & $\begin{array}{l}\text { Cadernos de História } \\
\text { da Educação }\end{array}$ & 2019 \\
\hline $\begin{array}{l}\text { As mães de famílias futuras: a Revista o Tico- } \\
\text { Tico e a formação das meninas brasileiras } \\
(1905-1925)\end{array}$ & PATROCLO & $\begin{array}{l}\text { Cadernos de História } \\
\text { da Educação }\end{array}$ & 2019 \\
\hline $\begin{array}{l}\text { Religiosa, imigrante, mulher: Irmãs } \\
\text { Missionárias de São Carlos Borromeo - } \\
\text { Scalabrinianas num olhar transnacional (1895- } \\
\text { 1917) }\end{array}$ & $\begin{array}{l}\text { LUCHESE; } \\
\text { MATIELLO; } \\
\text { BARAUSSE }\end{array}$ & $\begin{array}{l}\text { Revista Diálogo } \\
\text { Educacional }\end{array}$ & 2019 \\
\hline $\begin{array}{l}\text { Singularidade feminina no catolicismo: práticas } \\
\text { formativas em um caminho permeado de } \\
\text { "espinhos e rosas" }\end{array}$ & DANTAS & $\begin{array}{l}\text { Revista Diálogo } \\
\text { Educacional }\end{array}$ & 2019 \\
\hline $\begin{array}{l}\text { Jogos de poder e profissionalização docente: } \\
\text { discutindo as subjetividades do feminino na sala } \\
\text { de aula }\end{array}$ & $\begin{array}{l}\text { SANTOS; } \\
\text { FALEIRO; } \\
\text { OLIVEIRA }\end{array}$ & $\begin{array}{l}\text { Revista Ibero- } \\
\text { Americana de } \\
\text { Estudos em } \\
\text { Educação }\end{array}$ & 2019 \\
\hline TOTAL & \multicolumn{3}{|c|}{20} \\
\hline
\end{tabular}

Fonte: Elaboração própria (2020)

\section{Resultados e Discussão}

Os estágios aqui empreendidos retomam a conceitualização de Análise de Conteúdo, de Bardin (2011), que organiza o método de análise nas seguintes etapas: I. Organização da análise; II. A codificação; III. A categorização; IV. Inferências. Assim, o Estado da Arte aqui desenvolvido, teve esse percurso com o intuito de agregar as temáticas afins, resultando, nessa etapa, em 20 produtos.

Rev. Pemo, Fortaleza, v. 2, n. 2, p. 1-15, 2020

DOI: https://doi.org/10.47149/pemo.v2i2.3598

https://revistas.uece.br/index.php/revpemo

ISSN: 2675-519X

(c) (i) Esta obra está licenciada com uma Licença Creative Commons

Atribuição 4.0 Internacional. 
Rev. Pemo - Revista do PEMO

A leitura flutuante dos títulos, resumos e palavras-chave dos artigos, fez surgir, a partir das similitudes, três categorias em que temáticas comuns convergiram para 0 contexto da educação feminina: História da educação (10 artigos); Publicações (7 artigos); e Práticas docentes (3 artigos).

Nesta etapa, serão apresentadas as principais discussões tecidas pelos autores dos artigos, bem como suas contribuições para produção de saberes no campo da educação feminina nas suas múltiplas nuances.

\section{CATEGORIA HISTÓRIA DA EDUCAÇÃO}

Desse múltiplo campo de saberes, emergiu a maior quantidade de estudos, dez, ao todo. As temáticas desenvolvidas abordam o histórico discurso que idealiza a mulher como mais habilitada para lidar com as crianças pequenas no magistério primário (SANTOS; FALEIRO; OLIVEIRA, 2019), versa também sobre a historiografia de instituições escolares como o Educandário Nossa Senhora da Piedade, em Paraíba do Sul, que atendiam meninas desvalidas (NETO; HORA, 2018) ou ainda, trata da temática a partir da biografia de figuras femininas como Adelina Maioli, a primeira mulher a fazer parte do corpo discente do curso Técnico em Enologia, na cidade de Bento Gonçalves, Rio Grande do Sul (CAMARGO; EGGERT, 2019). Encontram-se também estudos realizados a partir do acervo documental do Colégio Municipal Pelotense, localizado na cidade de Pelotas, Rio Grande do Sul, sobre as primeiras professoras a compor o quadro docente no magistério secundário, (XAVIER; WEIDUSCHADT, 2016).

Nesse processo histórico de inserção profissional da mulher (MELO, 2019), aponta os estudos sobre a Escola Normal Nossa Senhora de Oliveira, em Oliveira, Centrooeste de Minas Gerais, bem como a implantação de escolas confessionais conduzidas por congregações femininas, modelo educacional largamente praticado no Brasil, como é o caso da Congregação Irmãs Missionárias de São Carlos Borromeo, no Rio Grande do Sul (LUCHESE; MATIELLO; BARAUSSE, 2019) e a Congregação das Irmãs Teresinhas, em Sergipe (DANTAS, 2019).

Rev. Pemo, Fortaleza, v. 2, n. 2, p. 1-15, 2020

DOI: https://doi.org/10.47149/pemo.v2i2.3598

https://revistas.uece.br/index.php/revpemo

ISSN: 2675-519X

(c) (i) Esta obra está licenciada com uma Licença Creative Commons

Atribuição 4.0 Internacional. 


\title{
PRÁTICAS EDUCATIVAS, MEMÓRIAS E ORALIDADES
}

\author{
Rev. Pemo - Revista do PEMO
}

Há estudos que buscam embasamento a partir de fontes, autores, documentos, jornais e periódicos diversificados, a fim de historicizar a formação docente feminina fazendo um apanhado a esse respeito, especificamente, a partir do final do século XIX até meados do século XX (GATI; MONTEIRO, 2016), ou a respeito de outros que recorrem à metodologia da história oral para constituir o percurso formativo de mulheres que foram protagonistas e tiveram notável reconhecimento na política, como é o caso de Maria Luiza Fontenele, primeira prefeita eleita de uma capital brasileira, Fortaleza (FIALHO E FREIRE, 2018).

Nas pautas das lutas femininas constavam o direito ao voto e o acesso à educação. Esse imbricamento foi problematizado a partir do percurso de quatro professoras feministas - Júlia Alves, Maria de Lourdes Lamartine, Martha de Medeiros e Nísia Floresta - que se destacaram por sua articulação no contexto educacional e político do Rio Grande do Norte, na década de 1920 (GALVÃO, 2016).

\section{CATEGORIA PUBLICAÇÕES}

A segunda categoria em relação à quantidade, compreende sete produções que se debruçam sobre publicações como jornais, revistas, periódicos, material didático ou outros impressos que prescreviam padrões sociais voltados para as questões de comportamento, alimentação, vestuário etc.

Os estudos de (BEGOSSI; MAZO, 2015) analisam a influência de fontes impressas ao incentivo de ginástica como expressão de novos padrões estéticos do corpo feminino. No caso da coluna "Vamos preparar os quitutes" contida na revista feminina Jornal das Moças, na década de 1950, as publicações com esse teor culinário traziam nas entrelinhas modelos de família, que concebiam a ideia de que cabia à mulher o zelo, a manutenção do lar e o cuidado do marido e das crianças (PILLA, 2015). Já nas páginas da revista O Tico-Tico, constavam conhecimentos não escolares voltados à formação moral das meninas, que idealizavam a mulher como nascida para o casamento e para a maternidade, nesta ordem (PATROCLO, 2019). Os anúncios publicados no jornal A União, periódico paraibano, corroboram para padronizar comportamentos que fazem emergir

Rev. Pemo, Fortaleza, v. 2, n. 2, p. 1-15, 2020

DOI: https://doi.org/10.47149/pemo.v2i2.3598

https://revistas.uece.br/index.php/revpemo

ISSN: 2675-519X

(c) (i) Esta obra está licenciada com uma Licença Creative Commons

Atribuição 4.0 Internacional. 
Rev. Pemo - Revista do PEMO

relações de poder e de tensão entre os gêneros (VASCONCELOS; FIALHO; MACHADO, 2017).

Os livros paradidáticos também são fonte de constituição de padrões femininos. Os estudos que examinam os personagens femininos a fim de refletir sobre gênero e identidade, como no livro Tosco, de Gilberto Mattje (2009) representa o quanto as mulheres não falam de si ou por si (CUNHA; SILVA, 2018)

Estudos que objetivam tecer ponderações sobre a reverberação da educação para que as mulheres possam ascender a cargos de liderança, como a pesquisa desenvolvida por (RODRIGUES, 2018), na revista Exame, mostra que, teoricamente, as oportunidades são as mesmas para homens e mulheres com formações equivalentes, mas na prática, a figura masculina ainda representa mais da metade dos cargos ocupados.

A análise de uma coletânea de artigos de Betti Katzenstein publicados entre 1947 e 1948, no Caderno Feminino do Jornal Folha da Manhã do Rio de Janeiro, mostra que a estratégia da persuasão também pode ser uma característica didática feminina utilizada para instruir seus leitores acerca de assuntos relacionados ao comportamento social (BORSATO; CUNHA, 2016).

\section{CATEGORIA PRÁTICAS DOCENTES}

Nessa categoria, foram examinados os três trabalhos que versam sobre práticas pedagógicas de professoras. Neles, seus autores buscam explorar a gênese do contexto escolar no século XIX, mais especificamente, as práticas docentes de mulheres, a partir de estudos biográficos. A primeira delas é a professora Benedita da Trindade do Lado de Christo, que foi a primeira professora pública paulista, aprovada no primeiro concurso para uma cadeira feminina, em São Paulo (MUNHOZ, 2018). A segunda, trata da vida da educadora espírita Anália Franco, que trabalhava em prol da educação à infância desvalida, desenvolvia seus trabalhos voltados, principalmente, às crianças negras, destituídas dos direitos básicos da sociedade (SANTANA; MACIEL; SOUZA, 2015). A terceira evidencia a trajetória educativa da educadora feminista Celina Padilha, a partir de

Rev. Pemo, Fortaleza, v. 2, n. 2, p. 1-15, 2020

DOI: https://doi.org/10.47149/pemo.v2i2.3598

https://revistas.uece.br/index.php/revpemo

ISSN: 2675-519X

(c) (i) Esta obra está licenciada com uma Licença Creative Commons

Atribuição 4.0 Internacional. 
sua inserção no debate sobre educação sexual, coeducação e emancipação feminina no campo educacional carioca na década de 1930 (DIAS; JARA, 2017).

É salutar reconhecer que, diante dos estudos aqui realizados, descortina-se que a temática da educação feminina é abordada sob vários aspectos, já que os pesquisadores que foram trazidos para este Estado da Arte abrangem a historiografia de instituições escolares, trazem, em seus percursos a história de mulheres professoras e alunas, possibilitando, assim, pensar a prática educacional e a formação docente de mulheres de todo o Brasil, que por tanto tempo foi-lhes negado o direito de ultrapassar os limites do espaço doméstico.

\section{Considerações finais}

Este estudo, denominado Estado da Arte, objetivou construir um inventário das produções científicas publicadas no Portal de Periódicos CAPES/MEC, referente à educação feminina no Brasil, no recorte temporal de 2015 a 2019, uma vez que o problema posto tinha a finalidade de mapear as pesquisas publicizadas a fim de buscar estudos que abordassem discussões sobre o papel feminino na educação brasileira.

Convém salientar que a restrita quantidade de publicações envolvendo a temática da mulher em suas singulares trajetórias - formativa e educativa - demonstram a insuficiência de estudos que coloquem em relevo as mulheres e as peculiaridades das lutas por sua emancipação, sobretudo na educação brasileira.

Constatou-se, assim, a partir desta pesquisa denominada Estado da Arte que os descritores "história da educação" e "mulher", retornaram 76 estudos produzidos nos últimos cinco anos, destes, apenas 20 artigos foram usados neste estudo. Para a discussão dos resultados, foram desenvolvidas três categorias a partir do método da análise de conteúdo, elaboradas diante da leitura dos títulos, das palavras-chave e dos resumos: "História da educação", "Publicações" e "Práticas docentes".

Da categoria História da educação, que concentrou maior parte dos produtos, emergiram estudos que trazem biografias de professoras para desenvolver pesquisas a

Rev. Pemo, Fortaleza, v. 2, n. 2, p. 1-15, 2020

DOI: https://doi.org/10.47149/pemo.v2i2.3598

https://revistas.uece.br/index.php/revpemo

ISSN: 2675-519X

(c) (i) Esta obra está licenciada com uma Licença Creative Commons

Atribuição 4.0 Internacional. 
Rev. Pemo - Revista do PEMO

fim de compreender a inserção da mulher no contexto educacional no Brasil, papel idealizado no imaginário popular que tornava a mulher como a mais habilitada a desenvolver a educação das crianças menores por ser uma profissão considerada uma extensão da maternidade.

Nessa perspectiva, os estudos versam também acerca da história de instituições escolares como a Escola Normal, escolas agrícolas ou de instituições confessionais. Há textos que refletem sobre o percurso de professoras na política, exercendo cargos eletivos e ainda retratam a história de mulheres feministas que, a partir do contexto educacional, travaram inúmeras lutas pelo sufrágio feminino e pela democratização da educação.

Da categoria Publicações, os temas abordados nos sete artigos classificados retratam que os tópicos contidos em jornais, revistas e periódicos veiculados ao longo do século XX assim como nos livros paradidáticos que mesmo na atualidade versam acerca da valorização de padrões sociais voltados para as questões educacionais, comportamentais, alimentares, vestuário etc., compreendendo uma análise de assuntos que debatem esses múltiplos aspectos sobre o que se concebe como "campo feminino" e quais atribuições são idealizadas para este público, geralmente associando à mulher atividades que não ultrapassem os limites domésticos.

A categoria Práticas docentes revelou apenas três estudos em que os pesquisadores discutem sobre as práticas pedagógicas que ressaltam as biografias de professoras que se sobressaíram ao realizarem seus trabalhos. São três perspectivas distintas de abordagem. Benedita da Trindade do Lado de Christo, a primeira professora a passar no primeiro concurso público para professoras. Anália Franco, professora espírita que trabalhava em benefício das crianças pobres, negras, desamparadas, bem como a professora Celina Padilha, feminista que militava em prol dos direitos políticos, de expressão, ao ensino misto e pela emancipação das mulheres no início do século XX.

A análise de conteúdo dos artigos publicados em periódicos e mapeados para este trabalho, permitiu identificar que existem lacunas no que se refere à amplitude do contexto educacional envolvendo a atuação feminina. A título de exemplo, não foram encontradas pesquisas que tratam da atuação de mulheres no ensino superior, tampouco de mulheres

Rev. Pemo, Fortaleza, v. 2, n. 2, p. 1-15, 2020

DOI: https://doi.org/10.47149/pemo.v2i2.3598

https://revistas.uece.br/index.php/revpemo

ISSN: 2675-519X

(c) (i) Esta obra está licenciada com uma Licença Creative Commons

Atribuição 4.0 Internacional. 
Rev. Pemo - Revista do PEMO

negras. Ademais, são poucos os trabalhos que trazem a prática de professoras ao longo da história da educação.

Este estudo, realizado a partir do mapeamento feito no Portal da Capes, resultou em poucos trabalhos. O exame foi realizado com o quantitativo de vinte artigos, razão pela qual não permite tecer generalizações, contudo suscita a necessidade de haver estudos e publicações que contemplem as múltiplas possibilidades que implicam no reconhecimento da autonomia de todos aqueles que permeiam o contexto educacional, independente da raça, classe social, sobretudo de gênero. Estudos estes que possibilitariam constituir a história da educação de forma mais autêntica, já que as mulheres também fizeram/fazem parte deste contexto.

\section{Referências}

BARDIN, L. Análise de conteúdo. Tradução de Luís Antero Reto e Augusto Pinheiro. Edições 70. Lisboa. Portugal, 2011.

BEGO, A. Políticas públicas e formação de professores sob a perspectiva da racionalidade comunicativa: da ingerência tecnocrata à construção da autonomia profissional. Educação \& Formação, Fortaleza, v. 1, n. 2, p. 3-24, 2016. Disponível em: https://revistas.uece.br/index.php/redufor/article/view/98. Acesso em: 10 jun. 2020.

BEGOSSI, T. D.; MAZO, J. Z. Ginástica alemã e ginástica feminina moderna: práticas destinadas às mulheres. Cinergis, v. 16, n. 4, 2015.

BORSATO, C. R.; CUNHA, M. V. da. Possíveis fontes das estratégias didáticas de Betti Katzenstein. História e Cultura, v. 5, n. 1, p. 188-207, 2016.

CAMARGO, E. C.; EGGERT, E. As mulheres e a enologia no sul do país: a história do Colégio de Viticultura e Enologia na cidade de Bento Gonçalves-RS, Brasil (1959-2019). Cadernos de História da Educação, v. 18, n. 3, p. 656-671, 2019.

CUNHA, D. F.; SILVA, M. L. da. Personagens femininas do livro paradidático "Tosco": educação sobre gênero e identidade. Periferia, v. 10, n. 2, p. 181-202, 2018.

DANTAS, M. J. Singularidade feminina no catolicismo: práticas formativas em um caminho permeado de "espinhos e rosas". Revista Diálogo Educacional, v. 19, n. 63, p. 1446-1464, 2019. 
Rev. Pemo - Revista do PEMO

DIAS, A.; JARA, I. B. Educação e emancipação feminina em Celina Padilha, a "educadora transviada" (1927-1930). Revista Educação e Emancipação, v. 10, n. 4, p. 229-255, 2018.

FERREIRA, N. S. A. As pesquisas denominadas "Estado da Arte". Educação \& Sociedade, v. 23, n. 79, p. 257-272, 2002. Disponível em:

https://www.fe.unicamp.br/alle/textos/NSAFAsPesquisasDenominadasEstadodaArte.pdf. Acesso em: 20 de jun. 2020.

FIALHO, L. M. F.; FREIRE, V. C. C. Educação formativa de uma líder política cearense: Maria Luiza Fontenele (1950-1965). Cadernos de História da Educação, v. 17, n. 2, p. 343-364, 2018.

GALVÃO, L. M. Os entrecruzamentos das lutas feministas pelo voto feminino e por educação na década de 1920. Revista Direito e Práxis, v. 7, n. 1, p. 176-203, 2016.

GATI, H. H.; MONTEIRO, I. A. Educação e docência feminina no Brasil do Século XIX: avanços e desafios. Cadernos de História da Educação, v. 15, n. 3, p. 1146-1169, 2016.

GHEDIN, E.; FRANCO, M. A. do R. S. Questões de método na construção da pesquisa em educação. 2. ed. São Paulo: Cortez, 2011.

LIMA, J.; SANTOS, G. Valores, educação infantil e desenvolvimento moral: concepções dos professores. Educação \& Formação, Fortaleza, v. 3, n. 2, p. 153-170, 2018.

Disponível em: https://revistas.uece.br/index.php/redufor/article/view/275. Acesso em: 15 jul. 2020.

LOPES, A. de P. C. Legislação e processos educativos: A constituição da escola primária no Piauí (1845 a 1889). Educação \& Formação, Fortaleza, v. 4, n. 1, p. 50-65, 2019. Disponível em: https://revistas.uece.br/index.php/redufor/article/view/866. Acesso em: 30 jun. 2020.

LUCHESE, T. Â.; MATIELLO, M.; BARAUSSE, A. Religiosa, imigrante, mulher: Irmãs Missionárias de São Carlos Borromeo-Scalabrinianas num olhar transnacional (18951917). Revista Diálogo Educacional, v. 19, n. 63, p. 1418-1445, 2019.

MELO, R. S. M. de. Memórias de normalistas: inserção profissional de professoras.

Cadernos de História da Educação, v. 18, n. 1, p. 266-277, 2019.

MUNHOZ, F. G. Para além das prendas domésticas: a trajetória da mestra Benedita da Trindade no magistério feminino paulista. Revista Brasileira de História da Educação, v. 18, 2018.

Rev. Pemo, Fortaleza, v. 2, n. 2, p. 1-15, 2020

DOI: https://doi.org/10.47149/pemo.v2i2.3598

https://revistas.uece.br/index.php/revpemo

ISSN: 2675-519X

(c) (i) Esta obra está licenciada com uma Licença Creative Commons

Atribuição 4.0 Internacional. 
Rev. Pemo - Revista do PEMO

NETO, A.; HORA, D. Contornos da educação feminina: a proposta educativa do Educandário Nossa Senhora da Piedade, 1925-1930. Periferia, v. 10, n. 2, p. 158-180, 2018.

PATROCLO, L. B. As mães de famílias futuras: a Revista o Tico-Tico e a formação das meninas brasileiras (1905-1925). Cadernos de História da Educação, v. 18, n. 3, p. 731-748, 2019.

PERROT, M.. Minha História das Mulheres. 2 ed. 6aㅡ reimpressão. São Paulo: Contexto, 2019.

PILLA, M. C. B. A. Fontes para história da alimentação e patrimônio alimentar: a coluna "Vamos preparar os quitutes", no Jornal das Moças, nos anos 1950. Demetra:

Alimentação, Nutrição \& Saúde, v. 10, n. 3, p. 623-635, 2015.

RIOS, P. P.; CARDOSO, H.; DIAS, A. Concepções de gênero e sexualidade d@s docentes do curso de licenciatura em pedagogia: por um currículo Queer. Educação \& Formação, Fortaleza, v. 3, n. 2, p. 98-117, 2 maio 2018. Disponível em:

https://revistas.uece.br/index.php/redufor/article/view/272. Acesso em: 10 jul. 2020.

RODRIGUES, R. R. J. Educação profissional da mulher e a ascensão a cargos de liderança. Revista Labor, v. 2, n. 18, p. 64-77, 28 ago. 2018.

ROMANOWSKI, Joana Paulin; ENS, Romilda Teodora. As pesquisas denominadas do tipo" estado da arte" em educação. Revista diálogo educacional, v. 6, n. 19, p. 37-50, 2006.

SANTANA, R. S. de; MACIEL, A. R. de J. S.; SOUZA, J. E. "DE VOLTA AO COMEÇO": a (re) construção da trajetória e contribuições da educadora Anália Franco. InterEspaço:

Revista de Geografia e Interdisciplinaridade, v. 1, n. 2, p. 311-329, 2015.

SANTOS, W. B.; FALEIRO, W.; OLIVEIRA, H. J. de. Jogos de poder e profissionalização docente: discutindo as subjetividades do feminino na sala de aula. Revista Ibero-

Americana de Estudos em Educação, v. 14, n. esp. 2, p. 1375-1394, 2019.

SOARES, C.; VIANA, T. Jovita Alves Feitosa: memórias que contam a história da educação nas prisões cearenses. Educação \& Formação, Fortaleza, v. 1, n. 1, p. 140158, 2016. Disponível em: https://revistas.uece.br/index.php/redufor/article/view/96. Acesso em: 11 jul. 2020. 
Rev. Pemo - Revista do PEMO

VASCONCELOS, L. M. de; FIALHO, L. M. F.; MACHADO, C. J. dos S.. Educação, gênero e higienismo nos anúncios publicitários da Paraíba durante a Primeira República. Cadernos de História da Educação, v. 16, n. 2, p. 451-473, 2017.

XAVIER, B. de F.; WEIDUSCHADT, P. Entre arquivos e memórias: o acervo do Colégio Municipal Pelotense e a inserção de professoras secundaristas. Resgate: Revista Interdisciplinar de Cultura, v. 24, n. 2, p. 113-128, 22 dez. 2016.

' Francinalda Machado Stascxak, https://orcid.org/0000-0001-6152-4295:
UECE, Centro de Educação, PPGE.
Mestranda em Educação pelo Programa de Pós-Graduação em Educação - UECE, Especialista em
Formaçãa de Formadores e os processos de coordenação pedagógica da Educação Básica e do
Ensino Superior - UECE. Membro do grupo de pesquisa Práticas Educativas, Memórias e Oralidades
(PEMO).
Contribuição de autoria: Contribuiu com a sistematização dos dados e com a escrita do texto.
Lattes: $\underline{\text { http://lattes.cnpq.br/5931710025183515. }}$
E-mail: $\underline{\text { naldastascxak@gmail.com }}$

ii Maria Julieta Fai Serpa e Sales, https://orcid.org/0000-0002-1786-1339
UECE, Centro de Educação, PPGE.
Mestranda em Educação pelo Programa de Pós-Graduação em Educação - UECE, Especialista em
Psicopedagogia Clínica, Hospitalar e Institucional (UNICHRISTUS). Membro do Grupo de Pesquisa
Docência no Ensino Superior e na Educação Básica (GDESB).
Contribuição de autoria: Colaborou com a escrita do texto.
Lattes: $\frac{\text { http://lattes.cnpq.br/2607513877849906 }}{\text { E-mail: }}$
mariajulietafaiserpaesales@gmail.com

Editora responsável: Cristine Brandenburg

\section{Como citar este artigo (ABNT):}

STASCXAK, Francinalda Machado; SALES, Maria Julieta Fai Serpa e. Educação feminina no Brasil: o que dizem as pesquisas publicadas no Portal da Capes (20152019). Rev. Pemo, Fortaleza, v. 2, n. 2, p. 1-15, 2020. Disponível em: https://revistas.uece.br/index.php/revpemo/article/view/3598 